Data obtained from 230 antenatal clinics on their current approach concerning toxoplasmosis

\begin{tabular}{lc}
\hline & $\begin{array}{c}\text { No of } \\
\text { clinics }\end{array}$ \\
\hline Advice and information given: & \\
On listeriaosis and salmonellosis & 198 \\
On toxoplasmosis & 136 \\
Policies: & 32 \\
Existing policy on screening & 108 \\
Change of approach in past year & 97 \\
Issue of screening raised & \\
Women screened: & 5 \\
Routinely & 219 \\
On request & 51 \\
If cat owners & 104 \\
When flu-like symptoms reported & \\
\hline
\end{tabular}

advice, policies (written or unwritten), and screening for toxoplasmosis. These indicate that toxoplasmosis is actively considered in antenatal clinics but that practice varies widely and that consumer led, ad hoc screening occurs.

The survey sought information about senio midwives' knowledge of further diagnosis, treatment, and follow up of women with toxoplasma infection during pregnancy or during the baby's first year. Altogether 110 respondents did no know whether action would be taken in the event of the infection being diagnosed; 113 did not know what action would be taken. Only 110 were aware that babies born to women with a current infection would warrant investigation and follow up. One hundred and fifty two were satisfied with advice given concerning toxoplasmosis.

This survey indicates the lack of a coherent clinical approach to toxoplasmosis in pregnancy. It highlights potential gaps in the knowledge of an important group of health professionals (midwives). The Toxoplasmosis Trust considers that this matter should be addressed urgently by the production of guidelines recommending bes practice. Finally, the findings highlight the ad hoc nature of current screening policy and the need for a multicentre study on the incidence of toxoplasmosis in pregnancy to obtain the data necessary to unify clinics' approach.

I thank PPP Medical Trust for supporting this project.

CHRISTINE ASBUR

Toxoplasmosis Trust

London N19BE

1 Ho-Yen DO, Chatterton JMW. Congenital toxoplasmosis-why and how to screen. Reviews in Medical Microbiology 1990; 229-35.

2 Royal College of Obstetricians and Gynaecologists. Prenatal screening for toxoplasmosis in the UK. Report of a multidisciplinary working group. London: RCOG, 1992.

\section{Screening for cervical intraepithelial neoplasia}

EDITOR,-J Elizabeth Macgregor and colleagues show that the incidence of invasive cervical cance fell sharply in women aged 40-69 who had been well screened and had had the opportunity of repeat screening.' Screening was associated with a tendency to present at an earlier stage. Though their evidence clearly shows that treatment of cervical intraepithelial neoplasia influences the course of the disease, their attribution of the changes in the population incidence and mortality due to cervical cancer to the screening oversimplifies the matter.

They acknowledge that, as has been recognised for some time, ${ }^{2}$ cohort effects are seen in the incidence of cervical cancer. Data from the Yorkshire Cancer Registry suggest that women who were aged 40-60 during 1968-79 were members of a cohort with a high incidence. ${ }^{3}$ Women who are currently aged 40-60 include members of a cohor with a lower incidence. A rising incidence of invasive cervical cancer in women under 40 is also seen in the Yorkshire data and suggests that a new cohort of women with a higher incidence is coming through.

The difference in incidence between cohorts probably reflects the sexual behaviour of these women in their late teens and 20s. Popular history describes a freer pattern of sexual behaviour during the second world war. This is corroborated objectively by a doubling in the proportion of children born outside marriage during that period. ${ }^{*}$ Behaviour then reverted to a more restricted pattern, and the proportion of births outside marriage fell. Women whose early adulthood occurred in this period are members of the cohort with a lower incidence. The changes in behaviour from the 1960s onwards are, as Macgregor and colleagues point out, associated with an increased incidence of cervical cancer. That statistics on births outside marriage indicate behaviour associated with a relatively high incidence of cervical cancer is supported by the international comparative data in the table.

International data on births outside marriage and incidence of cervical cancer

\begin{tabular}{lcc}
\hline & $\begin{array}{c}\text { Incidence of } \\
\text { Births outside } \\
\text { marriage, } \\
1970(\%)\end{array}$ & $\begin{array}{c}1979-82 \\
\text { (cases } / 100000 \\
\text { population) }\end{array}$ \\
\hline Country & 8.0 & 13.5 \\
United Kingdom & 11.0 & 18.5 \\
Denmark & 6.9 & $14.3^{\star}$ \\
France & 7.2 & 13.9 \\
West Germany & 2.1 & 7.6 \\
Netherlands & 1.4 & $5.9^{\star}$
\end{tabular}

Data from references 3 and 4

Spearman correlation coefficient $0 \cdot 8857, \mathrm{P}=0.05$

$\star$ Mean of figures from two cancer registries.

Macgregor and colleagues refer to "a concomitant rise in preinvasive disease," but they provide no data on its age distribution. The data from Yorkshire region show a slightly skewed distribution, with a model age at $30 .^{3}$ If this pattern is reflected in north east Scotland then the increase in the incidence of invasive disease in younger women seems to be occurring despite the increase in the detection of preinvasive disease. The contribution of screening programmes to the epidemiology of cervical cancer at the present level of service provision and uptake still remains uncertain.

Cancer Medicine Research Unit,

S M CRAWFORD

University of Bradford,

Bradford BD7 1DP

Macgregor JE, Campbell MK, Mann EMF, S ranson KY. Screening for cervical intraepithelial neoplasia in north east Scotland shows fall in incidence and mortality from invasive cancer with concomitant rise in preinvasive disease. $B M \mathcal{F}$ 1994;308:1407-11. (28 May.)

2 Mould RF. Cancer statistics. Bristol: Hilger, 1983.

3 Yorkshire Cancer Registry. Report 1991 including cancer statistics from 1984-1988. Leeds: Yorkshire Regional Cancer Organisation, 1992.

4 Central Statistical Office. Social trends 24. London: HMSO,

\section{Schizophrenia among residents of hostels for homeless people}

EDITOR,-Jim Connelly and Rhys Williams suggest that our finding of a lower prevalence of schizophrenia among homeless people resident in hostels in 1992 than in 1966 is explained by selection bias. ${ }^{12}$ As we explained in our paper, the aim of sampling in 1992, as in 1966, was to produce a representative sample of people living in hostels for the homeless in Edinburgh. The provision of hostels has changed over the past three decades, with a considerable reduction in the number of places in direct access hostels. ${ }^{3}$ We thought it possible that the prevalence of schizophrenia would differ according to the type of hostel, and we therefore classified hostels into two types according to whether they were most like or least like the hostels in 1966. Connelly and Williams seem to assume not only that it was invalid for us to include some hostels in our survey but also that the prevalence of schizophrenia differed substantially between the two types of hostel. The prevalence of schizophrenia in our study was similar in the two types of hostel $(7 / 72(10 \%)$ in the most comparable and $5 / 64(8 \%)$ in the least comparable).

We reported our findings as objectively and cautiously as possible, and, as Connelly and Williams concede, we discussed the study's shortcomings. We could have emphasised the lower prevalence of schizophrenia much more in our discussion, but we chose to err on the side of caution. Connelly and Williams worry that our findings may be misrepresented. We hope that policymakers will be able to discern the strengths and weaknesses of the study themselves.

We are grateful to Connelly and Williams for finding an error in the table of our paper. Ninety seven $(49 \%)$ of the 198 people in the sample studied in 1992 were resident in the most comparable hostels, and diagnostic assessments were performed on 72 of these subjects. This error does not affect any of the analyses or conclusions.

JOHN GEDDES Senior registrar

SHEENA BAILEY

Research associate

GILL YOUNG

Research associate

CHRIS FREEMAN

Royal Edinburgh Hospital,

Edinburgh EH10 5HF

Consultant psychotherapis

RICHARD NEWTON Psychiatrist

Inner North Community Mental Health Services,

Carlton,

Australia

Academic Department of Psychiatry,

St Mary's Hospital,

London W2 1NY

1 Connelly J, Williams R. Schizophrenia among residents of hostels for homeless people. BMF 1994;308:1572. (11 June.)

2 Geddes J, Newton R, Bailey S, Young G, Freeman C, Priest R. Comparison of prevalence of schizophrenia among residents of hostels for homeless people in 1966 and 1992. BMf 1994;308: 816-9. (26 March.)

3 Craig T, Timms PW. Out of the wards and onto the streets? Deinstitutionalisation and homelessness in Britain. Fournal of Mental Health 1992;1:265-75.

\section{Skill mix in primary care}

EdToR,-Iona Heath emphasises that decisions on changes in skill mix should be driven by needs and not costs. ${ }^{1}$ At a time when demand for services is outstripping supply, however, an eye to costs is wise. The rapid development of the role of practice nurses was spurred by the availability of finance (reimbursement of $70 \%$ of the salary costs; the nurses perform fee for service tasks; and reimbursement for health promotion work) at least as much as by patients' needs. Practice nurses have been shown to be effective and popular with patients. Whether they are cost effective, however, is another matter.

Heath mentions that nurse practitioners in Burlington, Canada, saw only half as many patients as doctors and that Stillwell saw patients at 20 minute intervals. In a study by Fallon et al in Glasgow, ${ }^{2}$ where walk in clinics were held by nurses, the consultation time available was 15 minutes per patient in the mornings and 21 minutes per patient in the afternoon $(4 \cdot 1$ consultations per hour in the morning and 2.9 